\title{
CONSIDERAÇÕES A PROPÓSITO DE UM CASO DE POLINEVRITE ALCOÓLICA
}

\author{
(Observação elaborada no serviço de neurologia da Fac. de Med. \\ da Univer. de S. Paulo - Prof. Adherbal Tolosa)
}

\author{
ALVARO MARCONDES DA SILVA \\ Interno - Acadêmico da 1.a M. H. da Santa Casa \\ (Serviço do Prof. Alméida Prado). Estagiário da \\ Sessāo de Endocrinológia do Instituto Butantan.
}

O diagnóstico da polinevrite alcoólica não oferece grandes dificuldades, mórmente quando se trate de um caso típico como é o que constitue motivo desta publicação. No entanto, mesmo nestes casos podem surgir problemas de alto interesse, especialmente no que tange ao diagnóstico diferencial com outras afeç̧ões do sistema nervosó. Em tais eventualidades, urge sistematizar o exame neurológico e conduzir as pesquizas semiológicas de modo racional, afim de poder aproveitar todos os elementos uteis; qualquer omissão poderia dar margem a erro diagnóstico.

A observação que apresentamos elaborada sob a orientaçãō diréta dos Assistentes do Serviço de Neurologia, mostra a seqüencia normal que deve ter o exame neurológico e nos comentários finais, salienta as dificuldades do diagnóstico diferencial.

Ces, Lep. (S. N. - 5910), com 31 anos de idade, masculino, brasileiro, investigador de polícia, residente em S. Paulo. Examinado em Maio de 1941, na 1. M. H. da Santa Casa de Misericórdia de S. Paulo.

\section{I - ANAMNÉSE}

Queixa e duração - Fraqueza nas pernas há 8 meses e dores nas pantorrilhas há 6 meses.

História da moléstia - A doença do paciente se iniciou há cerca de 8 meses por uma fraqueza nas pernas, que consistia na-falta de força que ele sentia nos membros inferiores, quando andava muito.

Essa fraqueza, a princípio de pouca intensidade, foi progressivamente se tornando maior, obrigando-o, cada vez mais, a restringir o seu trabalho, durante o qual, ele tem necessidade de andar muito.

Alguns dias antes de entrar para este Serviço, em virtude dessa mesma fraqueza, sofreu duas quedas.

Ha cerca de 6 meses apareceram tambem dores nas pantorrilhas. Essas dores são como "agulhadas", de intensidade variável, às vezes muito, 
outras vezes pouco intensas, localizadas nos músculos da perna, às vezes irradiadas para a face dorsal do pé, outras vezes sem irradiação e não influenciadas pelo movimento ou repouso, aparecendo em qualquer destes estados. Ultimamente essas dores tem aparecido mais freqüentemente e com maior intensidade do que no princípio.

Interrogado sôbre os diferentes aparelhos, referiu que já era um homem doente, pois em seguida a um lauto almoço que se realizou mais ou menos naquela época, sentiu mal estar gástrico, teve suores frios, e tudo foi seguido de um período de diarréia em que perdeı o apetite e obrava um grande número de vezes por dia.

Tendo-se curado desta diarréia, sofreu durante algum tempo de caim. bras nas pernas, principalmente noturnas.

Tem tido ainda um ou outro período de diarréia e nunca mais tev" bom apetite.

Ultimamente vem emagrecendo muito, dizendo já ter perdido cerca de 15 quilos. Sente ainda fraqueza geral, já há algụm tempo.

Antecedentes pessoais - Nada sabe sobre as condições de nascimento.

Doenças: Teve sarampo e pneứmonia na infância. Não teve doenças: renéreas e sefilíticas. Tem resfriados raramente.

Desenvolvimento somático normal. Foi magro até a idade escolar e depois engordou e assim permaneceu até hoje.

Desenvolvimento mental normal, tendo se alfabetizado logo que inicioti seu curso primário.

Temperamento muito nervoso, se irritando facilmente.

Conduta social normal.

História sexual: masturbou-se na mocidade 'e começou a ter relaçōes sexuais normais, mais ou menos aos 15 anos.

Trabalho moderado; tem bôa disposição para o trabalho.

Tem máu apetite há 2 anos. A sua alimentação é variada, porẹm irregular na qualidade e na quantidade.

Bébe alcool ha 10 anos; a princípio bebia pouco, porem foi aumentando a quantidade, passando a tomar todos os dias alguns aperitivos e nos domingos e feriados 2 a 3 garrafas.de vinho ou 3 a 4 garrafas de cerveja. Ultimamente não tem tolerado bem o alcool, muitas vezes vomitando ein seguida à sua ingestão.

Fuma desde a mocidade e já há muito tempo fuma 1 a 2 maços de cigarros por dia.

Antecedentes familiares - Pais vivos e fortes; 3 irmãos vivos e fortes; 7 irmãos mortos (alguns de pneumonia e outros de causa ignorada); esposa viva e forte. Tem um filho sadio, com 2 anos de idade. Não ha casos. de moléstias nervosas na família.

\section{II - INSPECÇÃO GERAL}

Impressão geral: Paciente de aspecto geral doentio, depauperado; facies alcoólatra.

Peso: 56 quilos. Estado mutritivo: hiponutrido ou desnutrido. Altura: $1 \mathrm{~m}, 71$ - T'ipo morfológico: normótipo.

Paciente aparentando a idade que refere ter (31 anos); esqueleto senr dismorfias; musculatura hipotônica e atrófica (principalmente nos mem. bros inferiores) como veremos no exame neurológico; decúbito indiferente; a atitude em pé e sentada, assim como a marcha, serão descritos no exame neurológico. Panículo adiposo pouco desenvolvido; edema mole e depressivel na porção inferior das pernas e no pé. Pele de consistência e elasticidade um pouco diminuidas, ligeiramente seca, principalmente nas extremidades inferiores, onde é tambem um pouco fria, sendo normalmente quen- 
tes, as demais partes do corpo. Piodermites raras, de localizações variadas. Mucosas visiveis descoradas.

Gânglios sub-maxilares aumentados de volume, duros, não dolorosos; adenopatia inguinal de pequeno tamanlo; gânglios epitrocleanos palpáveis, de pequeno tamanho. Não há tibialgia, nem esternalgia.

\section{III — EXAME OBJETIVO ESPECIAL}

1. Segmento cefálico $-C r a ̂ n i o:$ simétrico, não apresentando exostoses, nem pontos: dolorosos.

Seios da face e mastoide: não dolorosos à percussão:

Olhos: conjuntiva bulbar, apresentando ligeiro desenho capilar. Musculatura extrinseca: nada apresentando de anormal. Musculatura intrinseca: pupilas isocóricas, reagindo bem à luz e para a acomodação; reflexo consensưal presente.

Nariz e ouvidos: nada apresentando de particular.

Bôca: đentes mal conservados, apresentando várias cáries, e algúmas falhạs, e uma raiz exposta (canino superior direito). Língua com ligeira saburra no dorso e hipotônica, com impressões dentárias, Amígdalas: um pouco aumen-ntadas de volume.

Garganta $e$ faringe: nada apresentando de particular.

2. Pescoço - Curto, simétrico. Tiroide palpavel, não aumentada de volume. Batimentos venosos duplos fisiológicos nas fossas jugulares. Batimentos arteriais supra-esternais, e ao longo das carótidas.

3. Torax e aparelho respiratório - Nada digno de nota à inspecçãc, Falpação, percussão e ausculta.

4. Aparelho cárdio-vascular - Ictus visivel e palpavel no $5 .^{\circ}$ intercosto, um pouco para dentro da linha hemi-clavicular, de pequena intensidade. Ausculta nada apresentando de particular. Pulso rítmico, de freqüência 74; regularmente tenso e amplo. T. A.: $135 \times 84$.

5. Abdomen e aparelho digestivo - Abdomen plano, de paredes flácidas, permitindo a palpação que nada revelou de particular. Fígado; yercutivel desde $05^{\circ}$ intercosto até o rebordo costal; não palpavel. Baço: apenas percutível em pequena área.

6. Aparelho gênito-urinário - Nada de particular.

\section{IV - EXAME NEUROLOGICO}

A) ESTADO PSÍQUICO - Atenção espontânea e voluntária em bom estado.

Não há perturbações psíquicas da percepção.

Memória em bom estado em suas diferentes modalidades: de fixação, de conservação, de evocação e de localização' no tempo.

Imaginação pobre.

Associação de idéias, julgamento, raciocínio, normais. nológica.

Conciência em bom estado. Bôa orientação auto, alo-psíquica, e cro-

Afetividade normal demonstrando saudade de seus parentes.

Vontade e atividade não alteradas, tendo bôa disposição para o tra. balho.

"Devemos concluir pois pela integridade do psíquismo, pelo menos no momento do exame"

B) ATITUDE - FÁCIES - EQUILIBRPO - Atitude: A atitude do paciente no leito é indiferente, permanecendo no mais das vezes no decúbitio 
dorsal; na posição sentada, os pés mostram-se ligeiramente caidos, esboçando o "pé equino" e na posição erecta, temos a assinalar" pequenas oscilações do corpo, que referimos no equilíbrio e a constante preocupação do paciente em se apoiar embora possa ficar de pé sem apoio, evidenciando assim a fraqueza que o mesmo sente nos membros inferiores.

Fácies: de alcoólatra. O paciente apresenta certos movimentos dos lábios (contração do orbicular dos lábios) que poderiam dar a impressão de movimentos invaluntários espontâneos, uma vez que ele os realiza quasi constantemente, porem são devidos a irritação de um dente (canino superior direito) mal conservado e que está com a raiz exposta.

Equilíbrio: Sinal de Romberg ausente, apresentando entretanto o paciente, de olhos fechados, algumas oscilações do corpo, de amplitude variável. Essas oscilações existem, em menor gráu, no paciente com olhos ahertos e na posição erecta.

E) MOTRICIDADE - 1. Voluntária - Os movimentos são eu. práxicos.

Todos os movimentos dos membros, do tronco e da 'face são possịveis, demonstrando a não existência de paralisias.

Quando se manda o paciente levantar do leito, ele executa esse movimento com uma certa lentidão, sempre procurando sustentar o corpoo, com as mãos apoiadas no leito; entretanto, convidado a fazer esse movimento sem apoiar as mãos, ele consegue executá-lo, evidenciando assim apenas uma certa falta de forças para sustentat o corpo.

Força muscular - Membros inferiores - $P e ́$ : bastante diminuida a dos flexores dorsais do pé, principalmente a esquerda; diminuida a dos flexores plantares do pé esquerdo e presente e normal a dos flexores plantares do pé direito.

Perna: bastante diminuida a dos extensores e flexores das pernas.

Coxa: diminuida a dos extensores da coxa, principalmente a esquerda e bastante diminuida a dos flexores da coxa, prinçipalmente à esquerda.

A força muscular dos adutores e abdutores da coxa, está diminuida, principalmente à esquerda.

Membros superiores - Força muscular de um modo geral diminuida para todos os movimentos e para ambos os braços.

Provas de deficit motor - Mingazzini: negativo - Pé de cadaver: negativo - Raimiste: negativo. Barrê: se bem que o angulo réto formado entre a perna e a coxa tenha permanecido o mesmo, a perna esquerda tombou um pouco para fóra do eixo mediano do corpo, desviando-se da vertical, em um ângulo de cerca de $50^{\circ}$.

2. Movimentação passiva.

a) As articulações não estạ̃o dolorosas, tanto à palpação como à movimentação, e são livres, não apresentando limitações em seus movimentos.

b) Tonus: Pela inspeç̧ão pode-se notar uma diminuição global de volume dos membros inferiores, com tendência a desaparecimento dos relevos musculares.

A palpação das massas musculares dos membros inferiores, desperta dores, que são mais intensas ao nivel dos gastrocnêmios.

Músculos dos membros inferiores flácidos, apresentando pantorrilhas em bandeira; músculos dos membros superiores um pouco flácidos.

A movimentação passiva está prejudicada porque o movimento de flexão da perna sore a coxa e desta sobre a bacia provoca dores nos músculos quadriceps; flexão do pé de amplitude normal; extensão do pé ampla, despertando dores, na face dorsal desse segmento do membro. 
Balanço passivo dos pés prejudicado, pois ao executar a manobra, o paciente acusa dores no lugar em que fixamos a mão, na perna, o que produz um certo gráu de contração mascular. Balanço passivo das mãos normal.

3. Automática - Fala, respiração, deglutição, e mąstigação normais. Mímica conservada.

Marcha: a marcha do paciente dá a impressão de uma marcha atáxica, talonante, pois em geral, ao andar, ele toca o sólo em primeiro lugar com o calcanhar, fazendo, às vezes, ruido mais ou menos intenso; entretanto, verifica-se também uma maior flexão dos joelhos que o normal, mais exagerada à esquerda e uma certa tendência a queda do pé durante a march̆a, aumentando o ângulo que o pé normalmente faz com a perna e fazendo com que, às vezes, o pé arraste no chão antes que o calcanhar realise o aspecto talonante da marcha. Não há aumento da base de sustentação. Acredito, pois, tratar-se de uma marcha escarvante em início, com un componente atáxico.

Movimentos associados da marcha presentes e normais.

Coordenações musculares: A não ser as pequenas oscilações do corpo, apresentadas pelo paciente, na postura erecta e de olhos abertos, como referimos no equilíbrio, não existem outros fenômenos que denunciem uma "atáxia estática".

Pesquisando a "atáxia dinâmica" encontramos normal a prova indexnariz; a prova calcanhar-joelho revelou, entretanto, uma ligeira incoordenação muscular, pois no mais das vezes, o paciente, não acerta o joelho com o calcanhar e deslisa este sobre a crista da tíbia, de modo não satisfatório.

A manobra de Frenkel revelou-se negativa para os membros inferiores.

Já se descreveu o componente atáxico encontrado na marcha; aqui cabe assinalar, que esses fenômenos de incoordenação muscular da marcha, se acentuam pelas manobras de Fournier.

Não há sinais de incoordenação de tipo cerebelar, quer na marcha, como já vimos, quer nas provas de Babinski è de Stewart e da diadococinesia que foram negativas.

\section{Involuntária}

a) espontânea: Não se notam movimentos coréicos, atetósicos, mioclonias, tics, espasmos, convulsões e tremores.

Já nos referimos a certos movimentos dos lábios, que não são movimentos involuntários espontâneos e sim causados pela irritação de um dente (canino superior direito) mal conservado e que está com a raiz exposta; esta nòssa afirmação já foi confirmada posteriormente, pois pela retirada do dente, cessaram esses movimentos.

b) provocada ou reflexa: Reflexos ósteo-tendinosos: Reflexos médio plantares abolidos, despertando dores no lugar da pancada.

Reflexos aquilianos abolidos. Está presente o reflexo idio-muscular dos gastrocnêmios, despertando dores vivas no lugar da pancada.

Reflexos patelares abolidos.

Reflexos do cuboide presentes e normais.

Reflexos peroneiro-femurais posteriores e tíbio-femurais posteriores ausentes.

Reflexos dos adutores presentes e diminuidos.

Reflexo médio pubiano presente e diminuido; até certo ponto prejudicado por acusar o paciente dores, no local da pancada (?)

Reflexos carpo-metacarpianos ausentes.

Reflexos cúbito-pronadores presentes e diminuidos.

Reflexos estilo-radiais presentes e diminudos.

Reflexos bicipitais presentes e diminuidos. 
Reflexos tricipitais presentes e diminuidos.

Reflexos olecranianos ausentes.

Reflexo masseterino presente e normal.

Reflexo naso-palpebral presente e normal.

Reflexo-oro-orbicular dos lábios presente e vivo (existe uma causá irritativa nessa região, como já foi assinalado).

Reflexos cutâreos e mucosos: Reflexo córneo-conjuntival presente e normal

Reflexos cutâneos-abdominais presentes e normais.

Reflexos cremastéricos superficiais: presentes e normais; r. cremastéricos profundos prejudicados, por sentir o paciente dores muito vivas pela compressão das massas musculares da coxa, não permitindo a execução da manobra.

Reflexo cutâneo-plantar presente e normal.

Não há sinal de Babinski.

Não existe clonus do pé, da rótula e da mão; não há trepidações.

F) SENSIBİLIDADE - Até certo ponto prejudicada, por não contarmos com a bôa vontade do paciente que se mostra irritadiço.

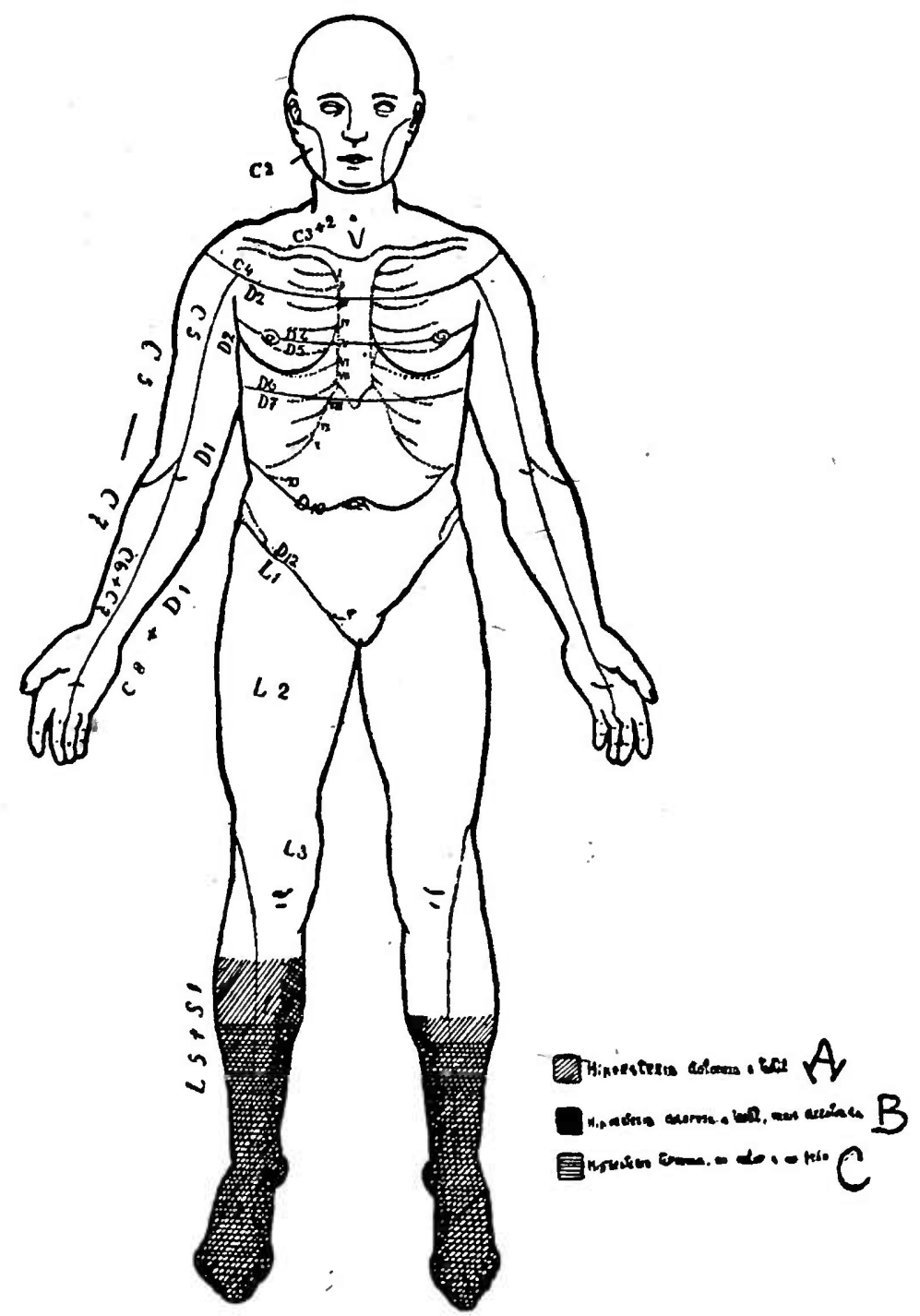

a) Subjetiva - Dores ao nivel dos membros inferiores, já referidas na anamnése.

Sensações parestésicas de formigamento, que aparecem inconstantemente ao nivel dos membros inferiores, e mais raramente ao nivel dos
superiores. 
b) Objetiva - Superficial - Hipoestesia ao tacto dos pés e da metade inferior da perna esquerda e $2 / 3$ inferiores da perna direita, mais acentuada na face interna de ambos os lados e de um modo geral, mais acentuadà à direita.

Sensibilidade dolorosa nas demais porções do corpo, presente e normal.

Hipoestesia dolorosa dos pés e da metade inferior da perna esquerda e 2/3 inferiores da perna direita, mais acentuada na face interna de ambos os lados e de um modo geral, mais acentuada à direita.

Sensibilidade dolorosa nas edmais porções do corpo, presente e normal. das pernas.

Hipoestesia térmica, ao calor e ao frio, dos pés e da metade inferior

Sensibilidade térmica nas demaís porções do corpo presente e normal.

Profunda - Sensibilidade segmentar ou artrestésica, abolida para os movimentos passivos dos grandees artelhos e presente e normal para os movimentos passivos dos demais segmentos do corpo.

Sensibilidade vibratória ou palestésica diminuida para os ossos do pé e da perna e presente e normal nas demais partes do corpo.

Sensibilidade para diferenciar pesos diferentes ou barestésica diminuida nas pernas e normal nas mãos.

Sensibilidade dolorosa profunda, pesquisada pela compressão da traquéia e dos testículos, presente e normal.

Sensibilidade estereognóstica presente e normal.

\section{RESUMO DO CASO}

Vamos assinalar os dados positivos que o nosso paciente apresenta .

\section{A) Da anamnése:}

Fraquezá nas pernas há 8 meses; Dores nas pantorrilhas há 6 meses; Períodos de diarréia intervalados com períodos em que obra normalmente há 2 anos; Emagrecimento; Fraqueza geral; Alcoolismo há 10 anos.

B) Do exame clínico:

Indivíduo muito emagrecido. Edema das extremidades inferiores. Pele sêca; fria nas extremidades inferiores. Piodermites. Anemia. Alguns gânglios infartados, de pequeno volume. Dentes mal conservados.

\section{C) Do exame neurológico:}

Facies de alcoólatra. Esbôço de "pé equino" Força musculār de um modo geral diminuida, sendo que nos membros inferiores apresenta diminuição irregular, conforme os grupos` musculares, ora bastante, ora pouco diminuida. Hipotonia muscular geral, com pantorrilhas em bandeira. Atrofias musculares, mais acentuadas nos músculos dos membros inferiores. Dores musculares pela compressão das massás musculares dos membros inferiores, mais intensas nos gêmeos. Marcha escarvante. Atáxia ligeira, de tipo sensitivo, verificável principalmente na marcha, onde se mostra mais acentuada pelás manobras de Fournier e verificável ainda com menor intensidade na postura erecta, e na prova calcanhar-joelho. Hiporeflexia ósteo-ten- 
corpo, as dores a compressão das masśas musculares, a marcha escarvante, a hiporeflexia ósteo-tendinosa, a ausência do sinal de BABINSKx, etc. tudo isto em conjunto, nos autoriza admitir a integridade dos neurôneos centrais do sistema piramidal ou néo-cinético.

Lamento, pelos motivos já expostos, não contar aqui com o exame elétrico que tornaria ainda mais nitida a minha afirmação; entretanto creio que os elementos apresentados, por si só, bastam para o nosso critério de certeza.

iDo mesmo modo, a ausência de movimentos involuntários espontâneos com presença de hipotonia muscular geral, a ausência de perturbações caracteristicas da motilidade automática, etc. ainda em conjunto, nos demonstra a integridade do sistema extrapiramidal ou páleo-cinético.

Ainda, a ausência de incoordenações musculares de tipo cerebelar nos permite concluir pela integridade desse sistema.

Por outro lado, a irregularidade das perturbações da sensibilidade apresentadas, tanto na sua qualidade como na sua extensão, nos permite supor a integridade dos feixes sensitivos com pontos de partida no interior do sistema nervoso central.

Desse modo, admitindo a integridade dos sistemas acima apontados; ou seja do sistema nervoso central, podemos tambem afastar do nosso pensamento aquelas doenças sistematizadas que, além do comprometimento do sistema nervoso periférico, apresentam no seu quadro mórbido, perturbaçoes outras, tais como, de neurôneos motores centrais, de feixes sensitivos com ponto de partida no interior do sistema nervoso central, etc...

Afastaremos portanto, a esclerose lateral amiotrófica que compromete a via piramidal, a eredo-ataxia espinhal de FrIEDREICH e eredo-atáxia cerebelar de PIÉRRE-Marie que comprometem os feixes espino-cerebelosos, além de lesões nos feixes piramidais, a hematomielia, a siringomielia, a esclerose em placas, os tumores, os síndromes de secção ou hemisecção da medula, a mielite aguda ascendente de LANDRY.

Ficamos assim, com a doença do nosso paciente localizada na patologia do sistema nervoso periférico, tal qual foi definido acima, e cabe-me então, nesśa patologia, fazer o diagnóstico diferencial entre as diferentes eventualidades mórbidas, entre as quais encontraremos aquela que o paciente apresenta.

Dentre essas eventualidades, podemos ainda afastar ,aquelas dependentes de nervos encefálicos, por não constatarmos perturbações referentes aos mesmos.

Ficamos assim, para o nosso estudo, unicamente com o sistema nervoso periférico espinhal, que deverá ser entendido como formado, pelos neurôneos motores em toda a sua extensão, desde a célula das pontas anteriores da medula até a terminação dos nervos nos músculos, e ainda mais pelo primeiro neurôneo sensitivo, com centro trófico nos glânglios espinhais, desde a sua terminação periférica até a sua terminação central. 
Dentre as moléstias que acometem esse sistema teremos portanto, as poliomielites anteriores, as radiculites anteriores, as funiculites, as nevrites e polinevrites e as radiculites posteriores.

Começaremos por afastar as "poliomielites anteriores agudas", em virtude do decurso lento e progressivo da moléstia, da ausencia de perturbações esfinctéricas e da idade do paciente, pois são raras as formas agudas de poliomielites acima de 20 anos.

A "atrofia muscular progressiva mielopática" tambem fica de lado, em se tratando de uma moléstia que tem um quadro mórbido bem típico que o noso paciente está longe de apresentar. De fato, ela se inicia na grande maioria des casos pela atrofia dos músculos da mão, dando a clássica mão de tipo Aran-Duchene, rárissimamente atinge os músculos dos membros inferiores e não dá perturbações da sensibilidade.

Resta-nos pois, unicamente discutir as doenças que atingem os nervos periféricos.

$\mathrm{Na}$ patologia dessa parte do sistema nervoso, KRAMER faz uma distinção entré nevrites e neurálgias de um lado e polinevrites de outro, dizendo que estas são moléstias gerais que invadem territórios nervosos que quasi sempre são respeitados pelas mononevrites. ou simplesmente nevrites e que seus sintomas são de carater difuso.

Diz mesmo "que cuando varios nervios sufren simultaneamente neuritis, el cuadro clinico general suele divergir del de la polineurites mereciendo más bien el nombre de mononeuritis múltiple"

No nośso caso, desde logo podemos admitir, pelo carater difuso dos sintomas, pela extensão dos territórios nervosos atingidos e pelo àspecto geral da doença que se trata de uma polinevrite e não de "mononeurites múltiplas".

As chamadas radiculites e as funiculites ficam desde logo excluidas, por falta de sintomatologia caracteristica: dôr provocada pela movimentação da coluna vertebral, topografia radicular dos distúrbios sensitivos, deficit motor de distribuição radicular nas radiculites e imobilisação da coluna vertebral em determinadas atitudes, por contratura antálgica dos musculos paravertebrais, dôr a percussão da região paravertebral nas funiculites.

Entretanto, devemos assinalar a "possibilidade de alterações concomitantes dos nervos periféricos e das raizes nervosas, o que em geral só acontece nas formas infecciosas das polinevrites e portanto afastando-se do nosso caso que, como veremos adiante, é. uma forma tóxica.

Ficamos assim, para o nosso diagnóstico, unicamente com as polinevrites e as radiculites posteriores.

Entre as polinevrites a única que poderia apresentar o nosso paciente é a "polinevrite alcoólica", por ser o alcool o único fator etiológico capaz de explicar, neste caso, as perturbações nervosas que o mesntu apresénta. 
Entre as radiculites posteriores, a única que poderemos citar como até certo ponto se enquadrando no exame clinico do paciente, é a "tabes dorsalis", que é uma meningo-radiculite posterior e como tal pode ser encaixada nas moléstias do sistema nervoso periférico. Não nos referimos aqui aos casos em que haja nitida esclerose dos cordões posteriores da medula.

Cabe-nos agora, portanto, fazer o diagnóstico diferencial entre a "tabes dorsal" e as "polinevrites" uma vez que estas, às vezes apresentam uma sintomatologia que simula aquela.

Estas duas moléstias se assemelham na realidade em alguns pontos de vista; assim, é comum encontrarmos em ambas, a areflexia tendinosa e a hipotonia muscular e estes sinais o nosso doente os apresenta.

Além destes, entretanto, o doente apresenta outros sinais que poderiam nos conduzir ao diagnóstico de tabes, como o componente atáxico da marcha, dando-lhe um aspecto talonante e com as manobras de Fournier positivass, a atáxia ligeira de tipo sensitivo, verificável na postura erecta e na prova calcanhar-joelho e as perturbações da sensibilidade profunda (óssea e segmentar das extremidades inferiores); no entanto, outros sinais havidos como importantes para o diagnóstico dessa moléstia o nosso doenté não apresenta, assim não encontramos o sinal de Argyll-Robertson, o sinal de Romberg, a anestesia visceral e as perturbações esfinctéricas. Infelizmente, os reflexos cremasterinos profundos se acham prejudicados conforme já relatamos atrás, e por isso não pudémos contar com o sinal-de ToLosa de grande valor para o diagnóstico diferencial da tabes.

Entretanto, podemos acrescentar desde já que se o diagnóstico de tabes, fosse feito assim num primeiro exame, pesquizas posteriores, clínicas e humorais o afastariam definitivamente.

Realmente o nosso doente apresenta consideravel deficit na força muścular, o que não é peculiar a tabes e além disso, resultaram negativas todas as pesquizas relativas a sifilis, como ausência de antecedentes, ausência de sinais clínicos, WASSERMANN e KAHN no sangue negativas e WASSERMann e Steinfeld no liquor negativas.

Por outro lado, pode-se afirmar que o doente não apresenta a forma clássica da polinevrite alcoólica, pois que encontraram-se nele alguns distúrbios - perturbações da sensibilidade profunda e marcha ligeiramente atáxica - que são a expressão de perturbações encontráveis nas lesões do neurôneo sensitivo radicular posterior.

O exame clínico minucioso pois, nos permite fazer o diagnóstico de "polinevrite alcoólica" baseado principalmente no conjunto dos elementos positivos fornecidos pelo nosso exame e ainda pela ausência dos elementos acima apontados, como de grande valor para o diagnóstico de tabes.

Estes elementos positivos são os seguintes: 
Alcoolismo há 10 anos e portanto presença de um fator tóxico.

Considerável perda de força muscular.

Dores espontâneas nas pantorrilhas.

Períodos de diarréia há 2 anos, que provavelmente atuaram como fatores predisponentes da moléstia atual, pelo estabelecimento de um estado de pré-avitaminóse, necessário, segundo as teorias modernas, na patogerria das polinevrites.

Esbôço de pé equino.

Hipotonia muscular.

Atrofias musculares de tipo degenerativo.

Dores musculares a compressão.

Marcha escarvante.

Perturbações da sensibilidade, dando fenómenos`atáxicos como é verificável na forma pseudo-tábida das polinevrites.

As hipo e areflexias ósteo-tendinosas encontradas, com reflexos superficiais normais.

Hipoestesias superficiais de pequena extensão, nas extremidades inferiores, com distribuição não sistematisada.

Se esses elementos não bastassem parà em conjunto, nos dar a certeza do diagnóstico feito, temos ainda o exame do líquido céfalo-raquidiano que, pela sua importância e carater decisivo no quadro mórbido do paciente, deîxei propositadamente para o fim.

De fato, tratando-se no caso da tabes de uma meningo radiculite, teriamos forçosamente alterações liquóricas que no caso não foram encontradas, sendo o exame do L. C. R.' perfeitamente normal.

Por outro lado, como a tabes presupõe a existênciā da sífilis e esta não foi demonstrada não só pelas reações de Wassermann e Steinfeld no liquor, mas tambem pelas reações de Wassermann e Kahn no sangue creio que fica assim definitivamente afastada a possibilidade da tabes dorsal no nosso paciente.

Um outro elemento que poderá tambem ser levado em consideração para confirmar o nosso diagnóstico, se bem que seu valor seja relativo e só podendo ser apreciado no conjunto dos demais elementos, é o ligeiro aumento da taxa de bilirubina no sangue, demonstrando uma ligeira insuficiência hepática, como é comum nas polinevrites alcoólicas.

\section{EVOLUÇÃO}

Em poucas palavras quero assinalar, que dias após a entrada do paciente neste serviço e de the ser instituido um tratamento adequado, o 
mesmo foi acometido de uma pneumonia lobar que atualmente está em franco período de remissão.

Durante o período de febre alta o paciente apresentou perturbações psíquicas, confusão mental e delírio com um certo gráu de sistematização (alucinações auditivas e visuais terríficas e delírio persecutório) como $t$ comum nos estados de alcoolismo crônico.

Já assinalamos que essa doença impediu que se tivesse feito o exame 'elétrico, que era de grande valor no caso, e agora apenas quero me referir que o quadro mórbido do paciente, relativo a polinevrite, deverá ter pecrado, em seguida à pneumonia, uma vez que esta se instalou, num terreno muito intoxicado e de grande depauperamento, contribuindo para o aumento desses males.

De fáto, é o que pudemos constatar a "grosso modo" uma vez que convinha não perturbar o paciente, pela abolição dos reflexos bicipitais, tricipitais, estilo-radiais e cúbito-pronadores e pelo aparecimento de dores à compressão nos músculos dos membros superiores.

\section{TRATAMENTO DA POLINEVRITE ALCOÓLICA}

A profilaxia dessa moléstia é teoricamente maito simples, uma vez çue consiste na supressão do alcool. Entretanto na prática, verifica-se que realisando-se isso de modo brusco, às vezes o quadro clínico peora, com aparecimento de perturbações, principalmente do psiquismo, como delírios alucinatórios e perturbações cardíacas com taquicardia e sinais de insuficiência que podem terminar pela morte.

Desse modo, as vezes somos levados a fazer a supressão do alcool de maneira lenta, administrando diariamente pequenas doses decrescentes desse tóxico, até que o paciente possa suportar a sua ausência.

$O$ repouso absoluto na cama sobretudo quando ha perigo de insuficiência cardíaca está sempre indicado; devemos levar em conta a possibilidade de se produzir úlceras de decúbito que são evitadas por coxins de agua ou de ar.

E' conveniente tambem suster a roupa da cama com arcos para evitar que o simples peso da coberta determine o "pé equino"; este ainda poderí ser evitado por manorbras que impeçam a contratura dos extensores do pé.

Os resultados que se podem esperar unicamente com estes meios, de. pendem da extensão da lesão nervosa, pois as degenerações uma vez estabelecidas são irreversíveis e só podemos esperar que novas lesões não se estabeleçam; e que possivelmente regridam aquelas em início.

A cura das paralisias e das atrofias musculares se pode tentar com a eletroterapia, em seguida a ùm acurado exame elétrico, para se determinar os danos produzidos pela doença.

Podemos tambem associar ao método anterior as massagens praticadas com a devida regra e a ginástica passiva.

As massagens são meios eficazes para ativar a circulação, para combater o edema e para obter a restauração anatômica dos músculos doentes.

A ginástica passiva evita o estabelecimento de aderências fibro-tendinosas que depois de um período de imobilidade prolongada se produzem nas partes paralíticas.

Podemos ainda nos utilizar dos preparados fosforados, e dos preparados estriquíninicos com o fim de agir sobre as células nervosas dos cornos anteriores e ganglionares, cujas alterações nesta moléstia são de pequena gravidade ou ausentes.

Esses preparados agiriam, ativando a função dessas células nervosas e aumentando assim a nutrição das fibras lesadas, que delas dependem.

Podemos então dar a lecitina, quer sob a forma de alimentos (ovos, cérebro de vitelo, fígado...) quer sob a forma de injeções usando um preparado comercial qualquer. 
A estriquinina, que também aumenta a excitabilidade reflexa da medula espinhal, pode ser usada por via oral, em pilulas de $0,001 \mathrm{gr}$. $(2,4$, 6 pilulas ao dia) ou ainda em injeções hipodermicas em solução milesimal, injetando $0,001 \mathrm{gr}$. por dose e repetindo a injeção algumas vezes por dia. Aumentando prudentemente a dose se pode atingir ainda 0,004-0,006 gr. por dia, injetando-se 0,002 por dose. Não é conveniente e nem util supera: estas doses.

Durante o tratamento da polinevrite é util ainda prevenir perturbações. cardíacas, administrando conjuntamente cardiotônicos.



